\title{
Multiple Sclerosis: Are Protective Immune Mechanisms Compromised by a Complex Infectious Background?
}

\author{
Bernd Krone ${ }^{1,2}$ and John M. Grange ${ }^{3}$ \\ ${ }^{1}$ Institute of Virology, Centre for Hygiene and Human Genetics, University of Göttingen, Kreuzbergring 57, 37075 Göttingen, Germany \\ ${ }^{2}$ Laboratory Medicine Institute Kassel, Druseltalstraße 61, D-34131 Kassel-Wilhelmshöhe, Germany \\ ${ }^{3}$ Advanced Therapies Centre B2, London Clinic Cancer Centre, 22 Devonshire Place, London W1G 6JA, UK
}

Correspondence should be addressed to Bernd Krone, bkrone@medizinlabor.de

Received 9 August 2010; Revised 7 October 2010; Accepted 18 November 2010

Academic Editor: Noriko Isobe

Copyright (C) 2011 B. Krone and J. M. Grange. This is an open access article distributed under the Creative Commons Attribution License, which permits unrestricted use, distribution, and reproduction in any medium, provided the original work is properly cited.

The immunological background of multiple sclerosis (MS) manifests as an altered reactivity against a diverse range of infections, particularly with the Epstein-Barr virus. Although this could be only an epiphenomenon of a more generalised dysfunction of the immune system in MS, it is also possible that a complex infectious background forms the basis of a specific immune dysregulation finally causing the disease. It is thus suggested that the complex infectious background bears the key for an understanding of the immune pathogenesis of the disease. It appears probable that improved standards of hygiene cause regulatory defects in the immune system, allowing the abnormal expression of human endogenous retroviral (HERV) genes. On the basis of epidemiological observations we describe how a failure of expansion or an eclipse of a subfraction of self-antigen-specific CD8 ${ }^{+} \mathrm{T}$ cells mediating immune repair, and a deleterious mode of action of HERV gene products, could underlie the pathogenesis of MS.

\section{Introduction}

Studies on the viral aetiology of disease have traditionally focused on exogenous viruses, but more recently attention has turned to the role of human endogenous retroviruses (HERVs) which comprise around $8 \%$ of the human genome [1]. Although a number of diseases are associated with abnormal formation of HERV-encoded gene products, it is difficult to establish whether such genetic expression is a cause or an effect of the disease process. Multiple sclerosis (MS), the pathogenesis of which is poorly understood [2], provides an ideal opportunity for the study of the way in which HERVs may be involved in the various stages in the evolution of a disease $[3,4]$.

Although it is widely accepted that there are strong endogenous and exogenous components to the aetiology of MS $[5,6]$, extensive studies failed to incriminate a single endogenous or exogenous agent $[7,8]$. Instead they point to a complex infectious background to the pathogenesis of the disease involving a multitude of exogenous infectious agents and to a compromised immunological protective background $[9,10]$. The causal relationship of any given agent to the aetiology of MS is difficult to determine as most or all the putative agents infect most human beings at some stage of their lives. On the other hand, the HERVs coded for by the human genome are part of the genetic background of all humans $[3,4,11]$. Accordingly, any causative agent may well be obscured.

\section{Human Endogenous Retroviruses in MS}

Human endogenous retroviruses (HERVs) have entered the human germ line successively over a period of millions of years $[3,4,11]$, and are present in the genome of all host cells. Most HERVs are defective, having been inactivated by negative selection and an accumulation of mutations (deletions, termination codons, and frame shifts) and thus most of their genetic loci are inactive [12, 13]. Some reading frames have, however, maintained open and code for a complete protein, such as the ERVWE1 locus on chromosome 7q21 which codes for syncytin-1, and one member of the HERV-W family, the multiple sclerosisrelated virus (MSRV), can form complete virions under certain circumstances [14]. Moreover, it is well established that 
certain exogenous human retroviruses, HTLV-I and HIV, as well as endogenous retroviruses in other species, such as rodents, ovines, and birds, can be cause of neurological and malignant diseases [15].

In this respect it is of interest that the presence of HERV sequences, and in particular those of the $\gamma$-retroviruses HERV-W/MSRV and of HERV-H/F, have been found in association with MS [12, 16, 17], that the expression of ERVWE1/MSRV in brain tissue from MS patients has been reported $[18,19]$, and that the presence of such sequences in the CSF has been claimed to be higher in MS than in controls [14, 20, 21]. Another group claimed that it is only syncytin that is expressed at higher levels in brains of MS patients [22], although the techniques used to show this have been criticised [23]. In addition, increased levels of antibody reactivity to specific $\gamma$-retroviral HERV Gag and Env epitopes have been found in serum and CSF from MS patients [12], and these antibody levels are related with the activity of the disease [4]. The HERV-W encoded Env (ERVWE1, syncytin) is upregulated in glial cells in active MS lesions and, when expressed as a construct in astrocytes, has been shown to induce oligodendrocyte cell death via redox-reactants [24], as well as inducing an autoimmune cascade [3].

Despite of 20 years of research, the role of HERVs as pathogens is still controversial but, nevertheless, they are the leading candidates for a link between genetic predisposition and environmental factors in a disease such as MS.

\section{Are Exogenous Viruses and Chlamydia Involved in the Pathogenesis of MS?}

Besides the HERVs as described above, there are at least three groups of exogenous infectious agents that can be grouped according to the nature of the observations that putatively link them to MS. The first group is exemplified by measles, varicella, and herpes simplex viruses, but it may contain many more potential members. The second group comprises the human herpes virus 6 (HHV-6) and Chlamydia pneumonia and the third group is represented only by the Epstein-Barr virus (EBV) which has emerged as the leading candidate among the putative pathogens.

In the premeasles vaccination era it was observed that, in the history of MS patients, there were more clinically manifest cases of measles that were experienced only later in life, as compared with controls [7, 8]. Moreover, the concentration of measles-specific antibodies was shown to be consistently higher in MS patients $[7,8]$. The introduction of measles vaccination in early childhood, however, had no striking impact on the epidemiology of MS $[8,25]$. A similar situation is observed with infection by varicella as, in contrast to previous studies on mostly adult patients, observations on a cohort of children showed that a history of chickenpox was associated with a reduced risk of MS (Odds ratio 0.58) [26].

Since the differences between prevalence of infectious disease or of a specific antibody between the patient and control groups are small, large groups must be studied to reveal significant differences. On this basis, at least 12 candidate infections, including measles and varicella, could have an association with MS [7-9, 27]. Problems of interpretation of such findings are illustrated by herpes simplex. Although MS patients have a higher prevalence of antiherpes simplex type 2 (HSV-2) antibody as compared with controls, this does not reflect a higher prevalence of HSV-2 infections in the patients; the reason being an elevated concentration of specific antibodies generated by infection with herpes simplex virus 1 (HSV-1) that cross-react more strongly in MS patients than in controls with the diagnostic HSV-2 antigen [9]. Moreover, a recent study on patients with MS commencing in childhood permitted a check in parallel for an association of specific infections to MS by means of elevated specific antibody. This identified measles, varicella, and herpes simplex viruses $(P<.0001)$ as the leading candidates, whereas an MS association for others including influenza, parainfluenza and rubella viruses $(P=.035$, .029 and .054, resp.), was less clear, questionable, or not confirmed [9]. Although there are interpretational problems, these observations find a parallel in studies on the synthesis of specific antibodies in the brain against the same range of pathogens, namely measles, varicella, herpes simplex, and rubella [28-30].

Association of infections with human herpes virus 6 (HHV-6) and Chlamydia pneumoniae (Cpn) to MS are weaker but serological parameters differ qualitatively from controls and it is possible that active, possibly chronically active, infections with these pathogens synergize with EBV to produce a dysregulated immune response. These two infections are significantly associated with MS. Thus elevated IgM antibody levels against Cpn in paediatric MS patients are indicative of current or recent active infection at the time of onset of MS [9]. A meta-analysis of 26 studies showed that, despite interstudy variability, patients with MS were significantly more likely than healthy controls or those with other neurological diseases to have detectable levels of Cpn DNA in their CSF, although the authors concluded that this finding did not establish an aetiological relationship [31]. In the case of HHV-6, repeated phases of coinciding virus activity with EBV in patients with MS have been described [32]. Moreover, there is an interesting series of systematic studies on targets of specific B and $\mathrm{T}$ cells that are detected more frequently in MS as compared with controls [33, 34]. These studies were originally intended to identify the potential target(s) of autoimmune processes. It was, however, not possible to confirm the higher frequency of such B and T cells specificities in subsequent studies, but other specificities became apparent and another aspect emerged. All the MSassociated epitopes had sequences homologous to those in proteins of EBV, HHV-6 as well as of Cpn, indicative of some interrelationship between the immune responses against the three different pathogens [10].

\section{Observations on EBV Infection}

In recent years interest has focused on the role of infection with EBV in the aetiology of MS [35-38]. A meta-analysis has established that $>95 \%$ of all patients with MS have serological evidence of prior EBV infection, compared to $87 \%$ in control subjects [39]. There is, however, no serological evidence of 
reactivation or active EBV infection in the patients at the time of onset of MS [9, 37, 40], and claimed extensive EBV infection of lymph follicles in the brain of MS patients [41] was not confirmed in subsequent studies [42-44] and remains an open question [45]. Furthermore, there is a lag phase of several years or a decade or more between EBV infection in the patients and the clinical manifestation of MS [46]. During this rather long time period, EBV-specific antibody may well have dropped below detectable levels in some persons. Also, taking into account the distribution of specific antibody concentrations in the study groups, it is not only possible but indeed likely that in the patient group there are virtually no EBV-naïve persons and, accordingly, past EBV infection has been postulated as a necessary condition for development of MS [9, 10, 37]. Accordingly, primary EBV infection appears to be extremely rare in those with established MS [46], and in a longitudinal followup of a large cohort of EBV-negative young adults, MS was observed to occur only subsequent to EBV infection [47].

In addition some qualitative differences were apparent in the antibody response to EBV in the patients with MS and the controls; in particular, the former had notably elevated antibody levels against the EBNA-1 protein of EBV [30, 37, $40,48,49]$. The local synthesis of anti-EBNA1 antibody in CSF has been described in several studies [30, 49-53]. It was also demonstrated that the risk of developing MS increases with the level of antibody to this virus [48]. The link between EBV infection and the risk of MS is, however, unclear and is not easily determined in an adult population since the great majority of controls are, from the third decade of life, likewise infected by this virus.

Notwithstanding, there are a number of hypothetical mechanisms by which EBV might induce MS [36, 54$56]$, though none of those suggested convincingly explain the pathogenesis of the disease, and it appears more likely that other infections synergize with EBV to produce a dysregulated immune response years or a decade before the clinical onset of MS. Moreover, the pathology of MS, characterised by widespread blood-brain barrier defects and a multifocal involvement of grey and white matter, argues against a conventional role for a presumed viral aetiology [57].

\section{Darwinian Medicine}

Attention has recently focused on environmental factors associated with the increase in the incidence of several classes of disease in the industrially developed nations. The concept, forming the basis of the emerging discipline of "Darwinian medicine" [58], is that hygiene-related factors isolate the human population from micro-organisms, both pathogens and, probably more importantly, commensals, that are crucial to the establishment of beneficial immunoregulatory networks. Thus, in principle, an "interkingdom crosstalk" between microbes and the human host can establish patterns of immune reactivity that prevent various allergic, autoimmune, and inflammatory diseases while a failure of such cross-talk can facilitate them [59]. One consequence of improved hygiene is that certain infections that were previously regularly encountered in infancy now occur at a much later time in life and after other infections may have altered the patterns of immune responsiveness. Infection by EBV is a good example, and it has been postulated that various other infections acquired before EBV may affect immunoregulatory networks, thereby leading to an attrition or eclipse of those regulatory $\mathrm{T}$ cells $\left(\mathrm{T}_{\text {reg }} \mathrm{s}\right)$ that would otherwise protect against MS [10]. In this context, $\mathrm{T}_{\text {regs }}$, though essential to immune function, may in some circumstances induce harmful effects and have therefore been termed a "dangerous necessity" [60].

Accordingly, a critical determinant of MS risk could be a compromised number or activity of protective $\mathrm{T}_{\text {reg }} \mathrm{s}$ [61, 62]. During an active and specific T cell-mediated immune response there could well be a competition with other kinds of T cells, most likely T-helper-cells, recognising the same epitope as the $T_{\text {regs }}$ or epitopes closely spatially situated on the relevant antigen(s). As a consequence certain Thelper cell populations, that induce production of specific antibody, could become expanded and, thus, account for the diverse rise in antibody levels as epiphenomena with little or no pathologic importance. Notwithstanding, the local production of measles, varicella, or rubella-specific antibodies in the central nervous system can be useful for diagnosis [28-30], and the production of anti-HERV antibodies may become of use as prognostic factor for MS disease $[4,63]$.

\section{Target Epitopes and HLA-Polymorphism}

On the supposition that the diverse MS-associated infectious agents express epitopes that generate regulatory and effector $\mathrm{T}$ cells involved in the prevention of, or an enhancement of risk of, MS, the challenge was to identify the relevant epitope or epitopes.

The EBV EBNA-1 protein is the most likely candidate to express an epitope that could affect $\mathrm{T}_{\text {reg }} \mathrm{s}$, since the concentration of specific antibody against this protein is, as mentioned above, particularly and significantly elevated in MS, in both children and adults $[9,64]$. Moreover, the EBNA-1 protein is expressed in latent EBV infection, and T cells recognising EBNA-1, play a key role in immune control of EBV in healthy persons [64]. Under these circumstances the number of epitopes of T-helper cells recognised on EBNA-1 is very limited but in MS many more epitopes across the entire C-terminal domain of the protein are recognised [65]. This "epitope spreading" could well be induced by prior and/or simultaneous infections by the candidate pathogens mentioned above, notably HHV-6 and Chlamydia pneumoniae, as these bear many homologies to the additional epitopes on the EBNA-1 protein [10]. This altered epitope recognition could divert the immune response away from the single putatively protective $T_{\text {reg }}$ epitope (which is likely to be harboured within the sequence FENIAEGLRALLARSHVER) and to the generation of an alternative range of competing T-helper cells.

The further challenge is to determine the host target for protective and altered, nonprotective, patterns of immune 
reactivity, and a likely candidate would be an epitope of a HERV-W peptide since, beside the few functional HERV-W proteins mentioned above, there are some open reading frames that code for hypothetical HERV peptides [10]. A candidate HERV epitope with the amino acid sequence MPVPSAPST was identified on a hypothetical HERV peptide and shown to have homologies in all the pathogens to which elevated antibody concentrations are found in MS patients, including EBV, measles, varicella, HSV, Chlamydia, HHV-6, influenza, parainfluenza, rubella, and others [10]. It was postulated that the effector $\mathrm{T}$ cell specific for this candidate epitope would most readily cooperate with the above-mentioned $\mathrm{T}_{\text {reg }} \mathrm{s}$ to support a supposed MS-protective immune response when the homologies of the respective specific target sequences are present on the same viral protein. This situation is realized with three pathogens: measles, varicella/zoster, and herpes simplex virus (type 1 and 2) [10]. Interestingly, on the basis of elevated antibody concentration, measles, varicella/zoster, and herpes simplex virus 2 have a very clear association with MS in children $(P<.0001$, with Bonferroni-Holm correction for multiple testing), whereas the MS association of the other pathogens is dubious or unconfirmed [9]. It must be stressed that gene transcripts of 21 of 25 open-reading frames with an initiating start codon for the hypothetical HERV peptide have been found in association with MS [10]. This gene transcript is coded on the complementary strand of the HERV-W Env gene region. To our knowledge this would be the first example of genetic information on the noncoding DNA strand of the human genome being implicated in immune processes relevant to health and disease!

It is therefore possible in principle to use epidemiological data and genetic databases to identify candidate targets of the relevant immune cells, and verification may come from future studies on HLA polymorphism. The relevance of the HLA polymorphism, for example, in MS has been demonstrated very clearly $[66,67]$, but though over $99 \%$ of individuals appear to be genetically incapable of developing MS, no specific gene making a major contribution to susceptibility to MS has yet been identified. In the light of the framework presented here, there is a need to investigate whether the critical determining factor in such susceptibility is a genetically determined absence of, or defect in, HLA molecules able to present the relevant peptides for supposed MS-protective $\mathrm{T}_{\text {reg }} \mathrm{s}[61,62]$ and T-effector cells and the presence of HLA molecules presenting homologous peptides to competing $\mathrm{T}$ cells with other functions.

\section{Immune Repair Protecting against Disease Progression, Malignant Transformation, and Autoimmunity}

The suggested mechanism of pathogenesis of MS presented here, based on the infectious background of the patient, is a novel one, but it may have a precedent in the pathogenesis of what, at first view, appears a completely unrelated disease, namely, melanoma [68-70]. There are parallels between the two diseases as in both it has been postulated that a HERV associated pathology, based on expression of HERV-encoded genes and the presentation of HERV-encoded peptides by HLA molecules, may be of critical relevance to pathogenesis $[68,69]$. As proposed for MS, there is evidence that immune recognition of, and response to, such peptides contribute to the immune surveillance of the initiating events of the pathogenesis of melanoma years or decades before the onset of clinical disease. On the other hand, there are major differences between the two diseases, with MS being more complex. In the case of melanoma, the available evidence indicates that a major component of immune-mediated protection results from the induction, by a range of natural infections and vaccinations, of populations of effector $\mathrm{T}$ cells that cross-react with a HERV-encoded epitope, HERV-KMEL, on a peptide coded for by an open reading frame of a HERV-K, and expressed on the surfaces of malignantly transformed melanocytes [69-71]. Indeed, vaccination with BCG or vaccinia early in life, or with yellow fever vaccine in adults, confers around $50 \%$ protection against melanoma later in life $[68,72,73]$. There is, however, no evidence that the mechanism for eclipse of protective regulatory cells as postulated for MS plays a role in the pathogenesis of melanoma.

It must be emphasised that HERV-encoded peptides are self-antigens and thus, in principle, able to be recognized by self-specific $\mathrm{CD}^{+} \mathrm{T}$ cells, the developmental biology and function of which has attracted considerable interest in recent years [74-76]. These cells belong to a distinct genetic lineage and have different developmental requirements than those of conventional $\mathrm{CD}^{+} \mathrm{T}$ cells. They undergo clonal proliferation when activated by infectious agents or vaccines bearing homologous epitopes [77], and may persist as self-specific memory cells for long periods of time. It is, however, important to note that self-specific CD8 ${ }^{+}$ $\mathrm{T}$ cells do not necessarily result in autoimmune reactions deleterious for the host but can instead result in immune repair.

In this context, while much attention has been paid to cell-mediated immune reactions resulting in cytotoxicity, much less interest has been shown towards mechanisms of cell repair, particularly in circumstances where conservation of cells, such as in the central nervous system, is of great importance. One such repair mechanism that has been studied involves gangliosides of the neolacto series, especially LM1, which are transferred from leucocytes to target cells by direct cell-to-cell contact [78-81]. In this context, gangliosides may be involved in the process of methylation of DNA which is the most important means by which a somatic cell can repress or silence the genetic expression of HERV-encoded genes [82, 83]. Thus, differential display analysis of gene expression established that LM1 mediates suppression of retroviral RNA $[68,79]$. A mechanism for this is suggested by the finding that LMI induces S-adenosylhomocysteine-hydrolase, an enzyme essentially involved in the generation of active methyl groups required for the process of methylation, as well as inducing a kelch-1like protein, one of a family of proteins that mediate transcriptional repression [84]. 


\section{Overexpression of HERV Env Proteins}

The observations summarised above raise the question of how abnormal HERV expression can induce pathological changes at the cellular level and how these changes can be prevented $[3,70,84]$. One aspect that is dealt with in the various papers in this special issue of the journal is the diversity of mechanisms that induce autoimmune phenomena in MS, an aspect that has been critically reviewed elsewhere [85]. Another aspect is disturbed redox processes $[24,86,87]$, as oxidative stress is certainly implicated in demyelinating disorders [88].

Retroviral Env proteins are glycoproteins that are able to cause neuroinflammation, neurodegeneration, and endoplasmic reticulum stress [86]. In MS the ERVWE1 Env, syncytin-1, is particularly overexpressed in glia where it induces endoplasmatic reticulum stress leading to the induction of free radicals that damage nearby cells $[24,86,87]$. The involvement of different cell components has been demonstrated, notably ASCT1, a receptor for syncytin-1, and a neutral amino acid transporter which were selectively suppressed in astrocytes. Syncytin-1 induces the expression of the endoplasmatic reticulum stress sensor (OASIS) and overexpresion of this sensor in astrocytes increases levels of inducible NO synthase with ensuing oligodendrocyte injury. Studies on transgenic mice gave insights into the role and mechanisms of HERV Env proteins in causing neuroinflammation and autoimmune processes, and confirmed human observations [86].

In melanoma, epidemiological observations led to the suggestion that HERV-K Env induced biosynthesis of "melanoma-melanin" via reduced levels of glutathioneperoxidase $[68,88,89]$. This modification of melanin is able to incorporate more heavy metal ions as compared with physiological eumelanins, in particular mercury, and tends to become oxidatively charged. Melanoma-melanin, responsible for the black colouration of melanomas, is detectable in dysplastic and congenital naevi cells, the presumed precursors of melanoma, but not in normal melanocytes. Melanin pigments have a very long life span and oxidatively charged melanoma melanin can thus catalyse the formation of harmful long-living reactive oxygen species and radicals over long periods of time, whereas normal melanin destroys them. Affected cells are therefore very vulnerable to any kind of oxidative stress, paving the way to cell degeneration and to malignant transformation through chromosome damage [90].

Moreover, in melanoma, interest has focussed on a distortion of the immune response caused by expression of HERV-encoded proteins leading to tumour escape and autoimmune processes [69], although questions of cause and effect remain.

These considerations on melanoma raise the question of whether similar mechanisms involving HERV-encoded proteins and melanin pigments could operate in MS. Although there is no direct evidence, there are some suggestive factors. Among the several environmental risk factors for MS [6], a leading one is a low level of bioactive vitamin D3, but it is still controversial whether any and, if so, which of the many actions of this vitamin is critical for MS [91]. It has been suggested that low levels of this vitamin cause, via $\gamma$-glutamyl-transpeptidase, a reduction in the intracellular levels of glutathione, as has been demonstrated in rat astrocytes [92]. The risk-enhancing effect of low vitamin D3 levels appears to commence during early in utero development as persons born in November/December have the least MS risk while those born in May/June have the highest risk. This difference is statistically significant [93]. The long-lasting impact of this effect may result from favouring the peroxide driven biosynthesis of melanomalike melanin and by the long-living nature of the polymeric melanin redox pigments including pro-oxidative variants. Cigarette smoking, particularly when started early in life, is a risk factor for MS $[94,95]$, and for an early conversion to clinically definite multiple sclerosis [96]. The mechanism of this risk could be the generation of reactive oxygen species.

\section{Conclusions}

In view of the possible mechanistic link between the pathogenesis of melanoma and MS, further studies on the role of HERVs in MS, and their comparison with HERV-K in melanoma are indicated.

Although the two diseases under consideration, MS and melanoma, are quite different, there are parallels in that both conditions develop in tissues originating from the neural crest and that both can be explained in terms of "Darwinian medicine" $[58,69]$. A complex pattern of exogenous infections and activation of endogenous retroviruses is apparently underlying the aetiology of both conditions.

Combining the analysis of epidemiological data with genetic data bank entries of infectious pathogens and of humans, it is possible to identify deficits within the regulatory networks of the immune system. We are convinced that on this basis it will become possible in the future to establish rational preventive and therapeutic measures for MS.

\section{References}

[1] F. P. Ryan, Virolution, HarperCollins, New York, NY, USA, 2009.

[2] H. Lassmann, W. Brück, and C. F. Lucchinetti, "The immunopathology of multiple sclerosis: an overview," Brain Pathology, vol. 17, no. 2, pp. 210-218, 2007.

[3] H. Perron and A. Lang, "The human endogenous retrovirus link between genes and environment in multiple sclerosis and in multifactorial diseases associating neuroinflammation," Clinical Reviews in Allergy and Immunology, vol. 39, no. 1, pp. 51-61, 2010.

[4] T. Christensen, T. Petersen, S. Thiel, T. Brudek, S. EllermannEriksen, and A. Møller-Larsen, "Gene-environment interactions in multiple sclerosis: innate and adaptive immune responses to human endogenous retrovirus and herpesvirus antigens and the lectin complement activation pathway," Journal of Neuroimmunology, vol. 183, no. 1-2, pp. 175-188, 2007.

[5] A. Ascherio and K. L. Munger, "Environmental risk factors for multiple sclerosis. Part I: the role of infection," Annals of Neurology, vol. 61, no. 4, pp. 288-299, 2007. 
[6] A. Ascherio and K. L. Munger, "Environmental risk factors for multiple sclerosis. Part II: noninfectious factors," Annals of Neurology, vol. 61, no. 6, pp. 504-513, 2007.

[7] E. Norrby, "Viral antibodies in multiple sclerosis," Progress in Medical Virology, vol. 24, pp. 1-39, 1978.

[8] S. Haahr and P. Höllsberg, "The ability of candidate viruses to explain epidemiological findings in multiple sclerosis," in Genes and Viruses in Multiple Sclerosis, O. R. Hommes, H. Wekerle, and M. Clanet, Eds., Elsevier, Amsterdam, The Netherlands, 2001.

[9] B. Krone, D. Pohl, K. Rostasy et al., "Common infectious agents in multiple sclerosis: a case-control study in children," Multiple Sclerosis, vol. 14, no. 1, pp. 136-139, 2008.

[10] B. Krone, F. Oeffner, and J. M. Grange, "Is the risk of multiple sclerosis related to the 'biography' of the immune system?" Journal of Neurology, vol. 256, no. 7, pp. 1052-1060, 2009.

[11] A. Dolei and H. Perron, "The multiple sclerosis-associated retrovirus and its HERV-W endogenous family: a biological interface between virology, genetics, and immunology in human physiology and disease," Journal of NeuroVirology, vol. 15, no. 1, pp. 4-13, 2009.

[12] T. Christensen, "Association of human endogenous retroviruses with multiple sclerosis and possible interactions with herpes viruses," Reviews in Medical Virology, vol. 15, no. 3, pp. 179-211, 2005.

[13] T. Christensen, "HERVs in neuropathogenesis," Journal of Neuroimmune Pharmacology, vol. 5, pp. 326-335, 2010.

[14] G. Mameli, V. Astone, G. Arru et al., "Brains and peripheral blood mononuclear cells of multiple sclerosis (MS) patients hyperexpress MS-associated retrovirus/HERV-W endogenous retrovirus, but not human herpesvirus 6," Journal of General Virology, vol. 88, no. 1, pp. 264-274, 2007.

[15] R. A. Weiss, "The discovery of endogenous retroviruses," Retrovirology, vol. 3, article 67, p. 77, 2006.

[16] G. Laufer, J. Mayer, B. F. Mueller, N. Mueller-Lantzsch, and K. Ruprecht, "Analysis of transcribed human endogenous retrovirus $\mathrm{W}$ env loci clarifies the origin of multiple sclerosisassociated retrovirus env sequences," Retrovirology, vol. 6, article 37, p. 53, 2009.

[17] C. Roebke, S. Wahl, G. Laufer et al., "An N-terminally truncated envelope protein encoded by a human endogenous retrovirus W locus on chromosome Xq22.3," Retrovirology, vol. 7, article 69, p. 82, 2010.

[18] J. M. Antony, YU. Zhu, M. Izad et al., "Comparative expression of human endogenous retrovirus-W genes in multiple sclerosis," AIDS Research and Human Retroviruses, vol. 23, no. 10, pp. 1251-1256, 2007.

[19] S. Sotgiu, C. Serra, G. Mameli et al., "Multiple sclerosisassociated retrovirus and MS prognosis: an observational study," Neurology, vol. 59, no. 7, pp. 1071-1073, 2002.

[20] S. Sotgiu, G. Arru, G. Mameli et al., "Multiple sclerosisassociated retrovirus in early multiple sclerosis: a six-year follow-up of a Sardinian cohort," Multiple Sclerosis, vol. 12, no. 6, pp. 698-703, 2006.

[21] G. Mameli, L. Poddighe, V. Astone et al., "Novel reliable realtime PCR for differential detection of MSRVenv and syncytin1 in RNA and DNA from patients with multiple sclerosis," Journal of Virological Methods, vol. 161, no. 1, pp. 98-106, 2009.

[22] J. M. Antony, M. Izad, A. Bar-Or et al., "Quantitative analysis of human endogenous retrovirus-W env in neuroinflammatory diseases," AIDS Research and Human Retroviruses, vol. 22, no. 12, pp. 1253-1259, 2006.
[23] J. A. Garson, J. F. Huggett, S. A. Bustin et al., "Unreliable real-time PCR analysis of human endogenous retrovirusW (HERV-W) RNA expression and DNA copy number in multiple sclerosis," AIDS Research and Human Retroviruses, vol. 25, no. 3, pp. 377-378, 2009.

[24] J. M. Antony, G. Van Marle, W. Opii et al., "Human endogenous retrovirus glycoprotein-mediated induction of redox reactants causes oligodendrocyte death and demyelination," Nature Neuroscience, vol. 7, no. 10, pp. 1088-1095, 2004.

[25] C. Ahlgren, K. Torén, A. Odén, and O. Andersen, "A population-based case-control study on viral infections and vaccinations and subsequent multiple sclerosis risk," European Journal of Epidemiology, vol. 24, no. 9, pp. 541-552, 2009.

[26] Y. Mikaeloff, G. Caridade, S. Suissa, and M. Tardieu, "Clinically observed chickenpox and the risk of childhood-onset multiple sclerosis," American Journal of Epidemiology, vol. 169, no. 10, pp. 1260-1266, 2009.

[27] I. Steiner, P. Nisipianu, and I. Wirguin, "Infection and the etiology and pathogenesis of multiple sclerosis," Current Neurology and Neuroscience Reports, vol. 1, no. 3, pp. 271-276, 2001.

[28] D. Pohl, K. Rostasy, C. Jacobi et al., "Intrathecal antibody production against Epstein-Barr and other neurotropic viruses in pediatric and adult onset multiple sclerosis," Journal of Neurology, vol. 257, no. 2, pp. 212-216, 2010.

[29] H. Reiber, M. Teut, D. Pohl, K. M. Rostasy, and F. Hanefeld, "Paediatric and adult multiple sclerosis: age-related differences and time course of the neuroimmunological response in cerebrospinal fluid," Multiple Sclerosis, vol. 15, no. 12, pp. 1466-1480, 2009.

[30] V. Nociti, G. Frisullo, A. Marti et al., "Epstein-Barr virus antibodies in serum and cerebrospinal fluid from multiple sclerosis, chronic inflammatory demyelinating polyradiculoneuropathy and amyotrophic lateral sclerosis," Journal of Neuroimmunology, vol. 225, pp. 149-152, 2010.

[31] P. G. Bagos, G. Nikolopoulos, and A. Ioannidis, "Chlamydia pneumoniae infection and the risk of multiple sclerosis: a meta-analysis," Multiple Sclerosis, vol. 12, no. 4, pp. 397-411, 2006.

[32] P. Höllsberg, M. Kusk, E. Bech, H. J. Hansen, J. Jakobsen, and S. Haahr, "Presence of Epstein-Barr virus and human herpesvirus 6B DNA in multiple sclerosis patients: associations with disease activity," Acta Neurologica Scandinavica, vol. 112, no. 6, pp. 395-402, 2005.

[33] P. Höllsberg, H. J. Hansen, and S. Haahr, "Altered CD8 ${ }^{+}$T cell responses to selected Epstein-Barr virus immunodominant epitopes in patients with multiple sclerosis," Clinical and Experimental Immunology, vol. 132, no. 1, pp. 137-143, 2003.

[34] S. Cepok, D. Zhou, R. Srivastava et al., "Identification of Epstein-Barr virus proteins as putative targets of the immune response in multiple sclerosis," Journal of Clinical Investigation, vol. 115, no. 5, pp. 1352-1360, 2005.

[35] A. Ascherio and K. L. Munger, "99th Dahlem conference on infection, inflammation and chronic inflammatory disorders: Epstein-Barr virus and multiple sclerosis: epidemiological evidence," Clinical and Experimental Immunology, vol. 160, no. 1, pp. 120-124, 2010.

[36] A. Ascherio and A. Bar-Or, "EBV and brain matter(s)?" Neurology, vol. 74, no. 14, pp. 1092-1095, 2010.

[37] D. Pohl, B. Krone, K. Rostasy et al., "High seroprevalence of Epstein-Barr virus in children with multiple sclerosis," Neurology, vol. 67, no. 11, pp. 2063-2065, 2006. 
[38] B. Banwell, L. Krupp, J. Kennedy et al., "Clinical features and viral serologies in children with multiple sclerosis: a multinational observational study," Lancet Neurology, vol. 6, no. 9, pp. 773-781, 2007.

[39] O. Santiago, J. Gutierrez, A. Sorlozano, J. de Dios Luna, E. Villegas, and O. Fernandez, "Relation between EpsteinBarr virus and multiple sclerosis: analytic study of scientific production," European Journal of Clinical Microbiology and Infectious Diseases, vol. 29, pp. 857-866, 2010.

[40] J. W. Lindsey, L. M. Hatfield, and T. Vu, "Epstein-Barr virus neutralizing and early antigen antibodies in multiple sclerosis," European Journal of Neurology, vol. 17, no. 10, pp. 1263-1269, 2010.

[41] B. Serafini, M. Severa, S. Columba-Cabezas et al., "Epsteinbarr virus latent infection and BAFF expression in B cells in the multiple sclerosis brain: implications for viral persistence and intrathecal B-Cell activation," Journal of Neuropathology and Experimental Neurology, vol. 69, pp. 677-693, 2010.

[42] S. N. Willis, C. Stadelmann, S. J. Rodig et al., "EpsteinBarr virus infection is not a characteristic feature of multiple sclerosis brain," Brain, vol. 132, no. 12, pp. 3318-3328, 2009.

[43] L. A. N. Peferoen, F. Lamers, L. N. R. Lodder et al., "EpsteinBarr virus is not a characteristic feature in the central nervous system in established multiple sclerosis," Brain, vol. 133, article e137, pp. 3318-3328, 2010.

[44] S. A. Sargsyan, A. J. Shearer, A. M. Ritchie et al., "Absence of Epstein-Barr virus in the brain and CSF of patients with multiple sclerosis," Neurology, vol. 74, no. 14, pp. 1127-1135, 2010.

[45] M. P. Pender, "Does Epstein-Barr virus infection in the brain drive the development of multiple sclerosis," Brain, vol. 132, no. 12, pp. 3196-3198, 2009.

[46] S. Haahr, A. M. Plesner, B. F. Vestergaard, and P. Höllsberg, "A role of late Epstein-Barr virus infection in multiple sclerosis," Acta Neurologica Scandinavica, vol. 109, no. 4, pp. 270-275, 2004.

[47] L. I. Levin, K. L. Munger, E. J. O’Reilly, K. I. Falk, and A. Ascherio, "Primary infection with the Epstein-Barr virus and risk of multiple sclerosis," Annals of Neurology, vol. 67, no. 6, pp. 824-830, 2010.

[48] J. D. Lünemann, M. Tintoré, B. Messmer et al., "Elevated Epstein-Barr virus-encoded nuclear antigen-1 immune responses predict conversion to multiple sclerosis," Annals of Neurology, vol. 67, no. 2, pp. 159-169, 2010.

[49] M. Castellazzi, C. Tamborino, A. Cani et al., "Epstein-Barr virus-specific antibody response in cerebrospinal fluid and serum of patients with multiple sclerosis," Multiple Sclerosis, vol. 16, no. 7, pp. 883-887, 2010.

[50] M. Comabella, X. Montalban, A. Horga et al., "Antiviral immune response in patients with multiple sclerosis and healthy siblings," Multiple Sclerosis, vol. 16, no. 3, pp. 355-358, 2010.

[51] J. D. Lünemann, M. Tintoré, B. Messmer et al., "Elevated Epstein-Barr virus-encoded nuclear antigen-1 immune responses predict conversion to multiple sclerosis," Annals of Neurology, vol. 67, no. 2, pp. 159-169, 2010.

[52] E. Jaquiéry, S. Jilek, M. Schluep et al., "Intrathecal immune responses to EBV in early MS," European Journal of Immunology, vol. 40, no. 3, pp. 878-887, 2010.

[53] O. Santiago, J. Guiterrez, A. Sorlozano et al., "Relation between Epstein-Barr virus and multiple sclerosis: analytical study of science production," European Journal of Clinical Microbiology \& Infectious Diseases, vol. 29, pp. 857-866, 2010.
[54] D. Pohl and C. Avolio, "Epstein-Barr virus and multiple sclerosis," Journal of the Neurological Sciences, vol. 286, pp. 6264, 2009.

[55] H. Perron, C. Bernard, J. B. Bertrand et al., "Endogenous retroviral genes, Herpesviruses and gender in Multiple Sclerosis," Journal of the Neurological Sciences, vol. 286, no. 1-2, pp. 65-72, 2009.

[56] T. Korn, "Pathophysiology of multiple sclerosis," Journal of Neurology, vol. 255, supplement 6, pp. 2-6, 2008.

[57] L. M. Agius, "Contextual developmental history of evolving global and focal parameters in multiple sclerosis progression," International Journal of Molecular Medicine and Advance Sciences, vol. 5, pp. 1-5, 2009.

[58] G.A. Rook, Ed., The Hygiene Hypothesis and Darwinian Medicine, Birkhaeuser, Basel, Switzerland, 2009.

[59] S. Ehlers and S. H. E. Kaufmann, “. 99th Dahlem conference on infection, inflammation and chronic inflammatory disorders: lifestyle changes affecting the host-environment interface," Clinical and Experimental Immunology, vol. 160, no. 1, pp. 1014, 2010.

[60] Y. Belkaid, "Regulatory $\mathrm{T}$ cells and infection: a dangerous necessity," Nature Reviews Immunology, vol. 7, no. 11, pp. 875888, 2007.

[61] J. Haas, B. Fritzsching, P. Trübswetter et al., "Prevalence of newly generated naive regulatory $T_{\text {reg }}$ cells $\left(T_{\text {reg }}\right)$ is critical for $\mathrm{T}$ suppressive function and determines $\mathrm{T}_{\text {reg }}$ dysfunction in multiple sclerosis," Journal of Immunology, vol. 179, no. 2, pp. 1322-1330, 2007.

[62] C. Severson and D. A. Hafler, "T-cells in multiple sclerosis," Results \& Problems in Cell Differentiation, vol. 51, pp. 75-98, 2010.

[63] T. Brudek, T. Christensen, L. Aagaard, T. Petersen, H. J. Hansen, and A. Møller-Larsen, "B cells and monocytes from patients with active multiple sclerosis exhibit increased surface expression of both HERV-H Env and HERV-W Env, accompanied by increased seroreactivity," Retrovirology, vol. 6, article 104, p. 116, 2009.

[64] L. I. Levin, K. L. Munger, M. V. Rubertone et al., "Temporal relationship between elevation of Epstein-Barr virus antibody titers and initial onset of neurological symptoms in multiple sclerosis," Journal of the American Medical Association, vol. 293, no. 20, pp. 2496-2500, 2005.

[65] J. D. Lünemann, N. Edwards, P. A. Muraro et al., "Increased frequency and broadened specificity of latent EBV nuclear antigen-1-specific T cells in multiple sclerosis," Brain, vol. 129, no. 6, pp. 1493-1506, 2006.

[66] D. A. Hafler, A. Compston, S. Sawcer et al., "Risk alleles for multiple sclerosis identified by a genomewide study," New England Journal of Medicine, vol. 357, no. 9, pp. 851-862, 2007.

[67] D. S. Goodin, "The causal cascade to multiple sclerosis: a model for MS pathogenesis," PLoS ONE, vol. 4, no. 2, Article ID e4565, pp. 1-12, 2009.

[68] B. Krone, K. F. Kölmel, B. M. Henz, and J. M. Grange, "Protection against melanoma by vaccination with Bacille Calmette-Guérin (BCG) and/or vaccinia: an epidemiologybased hypothesis on the nature of a melanoma risk factor and its immunological control," European Journal of Cancer, vol. 41, no. 1, pp. 104-117, 2005.

[69] B. Krone and J. M. Grange, "Melanoma, Darwinian medicine and the inner world," Journal of Cancer Research and Clinical Oncology, vol. 136, pp. 1787-1794, 2010.

[70] S. Singh, S. Kaye, and M. E. Gore, "The role of human endogenous retrovirues in melanoma," British Journal of 
Dermatology, vol. 161, pp. 1225-1231, 2009, Erratum in British Journal of Dermatology, vol. 161, p. 1424, 2009.

[71] F. Schiavetti, J. Thonnard, D. Colau, T. Boon, and P. G. Coulie, "A human endogenous retroviral sequence encoding an antigen recognized on melanoma by cytolytic T lymphocytes," Cancer Research, vol. 62, no. 19, pp. 5510-5516, 2002.

[72] B. Krone, K. F. Kölmel, J. M. Grange et al., "Impact of vaccinations and infectious diseases on the risk of melanoma Evaluation of an EORTC case-control study," European Journal of Cancer, vol. 39, no. 16, pp. 2372-2378, 2003.

[73] G. Mastrangelo, B. Krone, E. Fadda et al., "Does yellow fever $17 \mathrm{D}$ vaccine protect against melanoma?” Vaccine, vol. 27 , no. 4, pp. 588-591, 2009.

[74] M. S. Jordan, A. Boesteanu, A. J. Reed et al., "Thymic selection of $\mathrm{CD}^{+} \mathrm{CD} 25^{+}$regulatory $\mathrm{T}$ cells induced by an agonist selfpeptide," Nature Immunology, vol. 2, no. 4, pp. 301-306, 2001.

[75] S. Dhanji and H. S. Teh, "IL-2-activated CD8+CD44 cells express both adaptive and innate immune system receptors and demonstrate specificity for syngeneic tumor cells," Journal of Immunology, vol. 171, no. 7, pp. 3442-3450, 2003.

[76] D. Mathis and C. Benoist, "Aire," Annual Review of Immunology, vol. 27, pp. 287-312, 2009.

[77] M. H. Kershaw, C. Hsu, W. Mondesire et al., "Immunization against endogenous retroviral tumor-associated antigens," Cancer Research, vol. 61, no. 21, pp. 7920-7924, 2001.

[78] K. Ritter, R. Hartl, G. Bandlow, and R. Thomssen, "Cytostatic effect of gangliosides present in the membrane of macrophages," Cellular Immunology, vol. 97, no. 2, pp. 248$257,1986$.

[79] L. Schaade, M. Kleines, R. Walter, R. Thomssen, and K. Ritter, "A membrane-located glycosphingolipid of monocyte/granulocyte lineage cells induces growth arrest and triggers the lytic viral cycle in Epstein-Barr virus genomepositive Burkitt lymphoma lines," Medical Microbiology and Immunology, vol. 188, no. 1, pp. 23-29, 1999.

[80] H. Nojiri, S. Kitagawa, M. Nakamura, K. Kirito, Y. Enomoto, and M. Saito, "Neolacto-series gangliosides induce granulocytic differentiation of human promyelocytic leukemia cell line HL-60," Journal of Biological Chemistry, vol. 263, no. 16, pp. 7443-7446, 1988.

[81] L. Schaade, M. Kleines, B. Krone, M. Hausding, R. Walter, and K. Ritter, "Enhanced transcription of the sadenosylhomocysteine hydrolase gene precedes Epstein-Barr virus lytic gene activation in ganglioside-stimulated lymphoma cells," Medical Microbiology and Immunology, vol. 189, no. 1, pp. 13-18, 2000.

[82] S. Stengel, U. Fiebig, R. Kurth, and J. Denner, "Regulation of human endogenous retrovirus-K expression in melanomas by CpG methylation," Genes Chromosomes and Cancer, vol. 49, no. 5, pp. 401-411, 2010.

[83] J. Gimenez, C. Montgiraud, G. Oriol et al., "Comparative methylation of ERVWE1/syncytin-1 and other human endogenous retrovirus LTRs in placenta tissues," DNA Research, vol. 16, no. 4, pp. 195-211, 2009.

[84] X. J. Wang, Z. Sun, N. F. Villeneuve et al., "Nrf2 enhances resistance of cancer cells to chemotherapeutic drugs, the dark side of Nrf2," Carcinogenesis, vol. 29, no. 6, pp. 1235-1243, 2008.

[85] P. O. Behan, "Futility of the autoimmune orthodoxy in multiple sclerosis research," Expert Review of Neurotherapeutics, vol. 10, no. 7, pp. 1023-1025, 2010.
[86] J. M. Antony, K. K. Ellestad, R. Hammond et al., "The human endogenous retrovirus envelope glycoprotein, syncytin-1, regulates neuroinflammation and its receptor expression in multiple sclerosis: a role for endoplasmic reticulum chaperones in astrocytes," Journal of Immunology, vol. 179, no. 2, pp. 12101224, 2007.

[87] J. M. Antony, A. M. DesLauriers, R. K. Bhat, K. K. Ellestad, and C. Power, "Human endogenous retroviruses and multiple sclerosis: innocent bystanders or disease determinants?" Biochimica et Biophysica Acta, vol. 1812, no. 2, pp. 162-176, 2011.

[88] W. H. Tolleson, "Human melanocyte biology, toxicology, and pathology," Journal of Environmental Science and Health-Part C, vol. 23, no. 2, pp. 105-161, 2005.

[89] F. L. Meyskens, P. Farmer, and J. P. Fruehauf, "Redox regulation in human melanocytes and melanoma," Pigment Cell Research, vol. 14, no. 3, pp. 148-154, 2001.

[90] A. Compston, C. Confavreux, and H. Lassmann, McAlpine's Multiple Sclerosis, Churchill Livingston, London, UK, 2006.

[91] J. Smolders, "Vitamin D and multiple sclerosis: correlation, causality, and controversy," Autoimmune Diseases, 3 pages, 2011.

[92] E. Garcion, L. Sindji, G. Leblondel, P. Brachet, and F. Darcy, "1,25-dihydroxyvitamin D regulates the synthesis of $\gamma$ glutamyl transpeptidase and glutathione levels in rat primary astrocytes," Journal of Neurochemistry, vol. 73, no. 2, pp. 859866, 1999.

[93] C. J. Willer, D. A. Dyment, A. D. Sadovnick, P. M. Rothwell, T. J. Murray, and G. C. Ebers, "Timing of birth and risk of multiple sclerosis: population based study," British Medical Journal, vol. 330, no. 7483, pp. 120-123, 2005.

[94] C. H. Hawkes, "Smoking is a risk factor for multiple sclerosis: a metanalysis," Multiple Sclerosis, vol. 13, no. 5, pp. 610-615, 2007.

[95] A. K. Hedström, M. Bäärnhielm, T. Olsson, and L. Alfredsson, "Tobacco smoking, but not Swedish snuff use, increases the risk of multiple sclerosis," Neurology, vol. 73, no. 9, pp. 696701, 2009.

[96] F. Di Pauli, M. Reindl, R. Ehling et al., "Smoking is a risk factor for early conversion to clinically definite multiple sclerosis," Multiple Sclerosis, vol. 14, no. 8, pp. 1026-1030, 2008. 


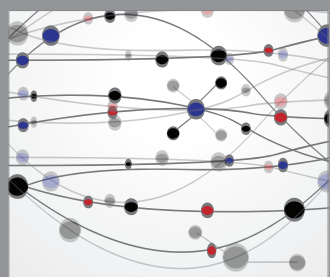

The Scientific World Journal
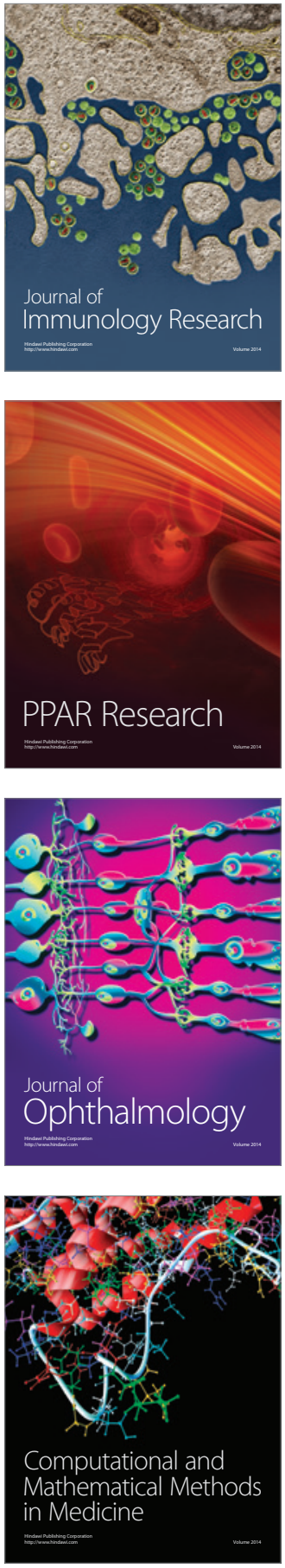

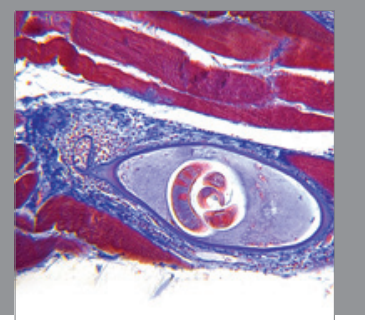

Gastroenterology

Research and Practice
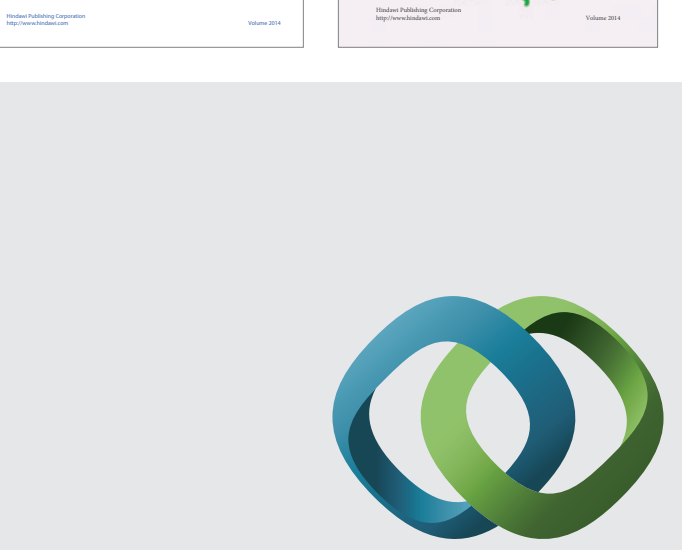

\section{Hindawi}

Submit your manuscripts at

http://www.hindawi.com
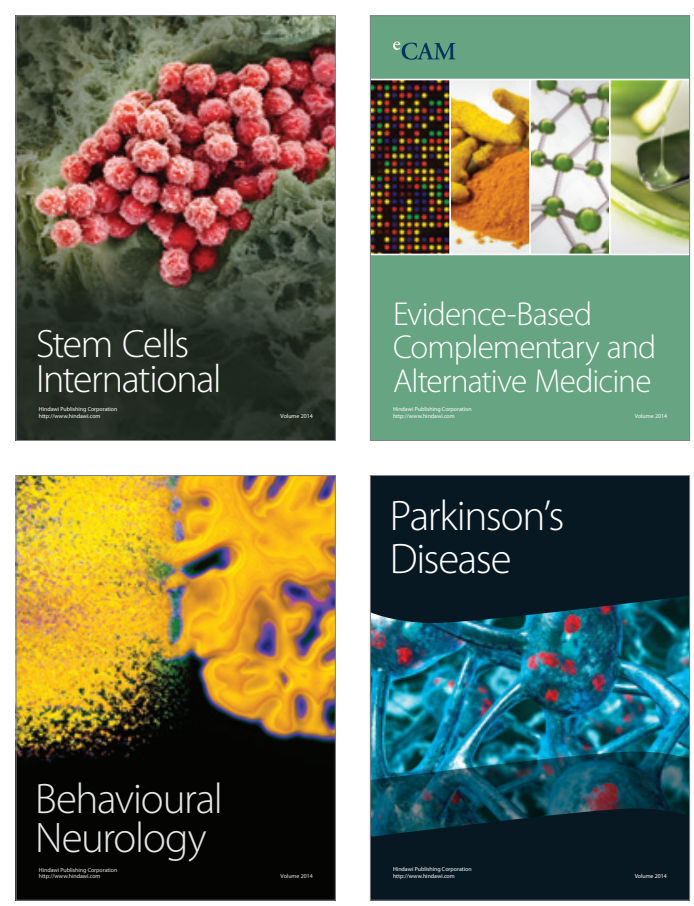

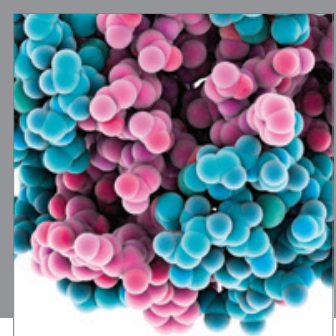

Journal of
Diabetes Research

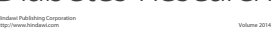

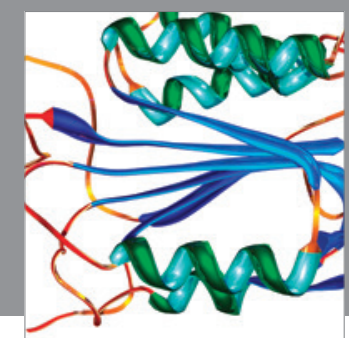

Disease Markers
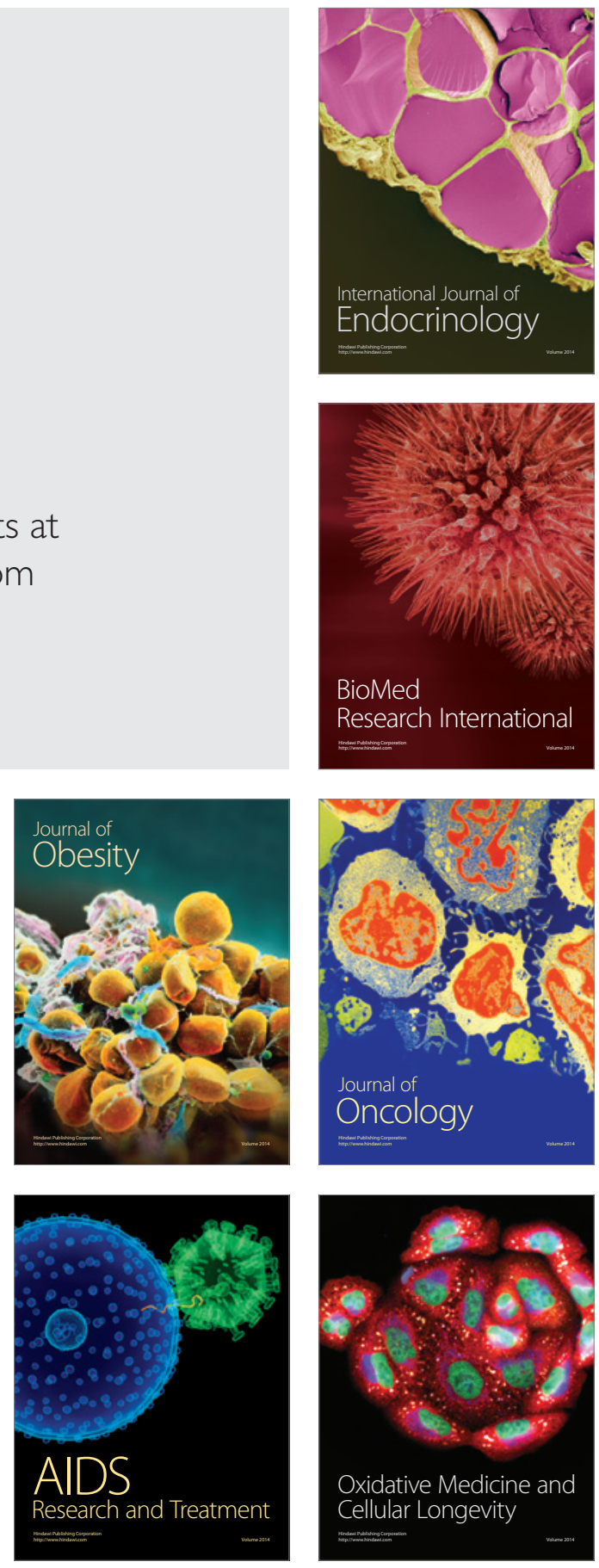